\title{
An outbreak of vancomycin-resistant Enterococcus faecium in an acute care pediatric hospital: Lessons from environmental screening and a case-control study
}

\author{
Steven J Drews PhD FCCM D(ABMM) ${ }^{1,2,3}$, Susan E Richardson MD FRCPC ${ }^{1,3,4}$, Rick Wray RN BHS CIC ${ }^{4}$, \\ Renee Freeman $\mathrm{RN} B S c N \mathrm{ClC}^{4}$, Carol Goldman $\mathrm{RN} \mathrm{BSCN} \mathrm{CIC}^{4}$, Laurie Streitenberger RN BSC $\mathrm{CIC}^{4}$, \\ Derek Stevens $\mathrm{PhD}^{5}$, Cristina Goia $\mathrm{MSc}^{5}$, Danuta Kovach $\mathrm{BA}^{4}$, Jason Brophy MD FRCPC ${ }^{3,4}$, \\ Anne G Matlow MD FRCPC $1,3,4$
}

\begin{abstract}
SJ Drews, SE Richardson, R Wray, et al. An outbreak of vancomycin-resistant Enterococcus faecium in an acute care pediatric hospital: Lessons from environmental screening and a case-control study. Can J Infect Dis Med Microbiol 2008;19(3):233-236.
\end{abstract}

BACKGROUND: The present study describes a vancomycinresistant enterococci (VRE) outbreak investigation and a case-control study to identify risk factors for VRE acquisition in a tertiary care pediatric hospital.

OBJECTIVE: To report an outbreak investigation and a case-control study to identify risk factors for VRE colonization or infection in hospitalized children.

METHODS: Screening for VRE cases was performed by culture or polymerase chain reaction. A case-control study of VRE-colonized patients was undertaken. Environmental screening was performed using standard culture and susceptibility methods, with pulsed-field gel electrophoresis to determine relationships between VRE isolates. Statistical analysis was performed using SAS version 9.0 (SAS Institute Inc, USA).

RESULTS: Thirty-four VRE-positive cases were identified on 10 wards between February 28, 2005, and May 27, 2005. Pulsed-field gel electrophoresis analysis confirmed a single outbreak strain that was also isolated from a video game found on one affected ward. Multivariate analysis identified cephalosporin use as the major risk factor for VRE colonization.

CONCLUSIONS: In the present study outbreak, VRE colonization was significantly associated with cephalosporin use. Because shared recreational items and environmental surfaces may be colonized by VRE, they warrant particular attention in housekeeping protocols, particularly in pediatric institutions.

Key Words: Cephalosporins; Outbreak; Pediatrics; Risk factor; VRE
Une éclosion d'Enteroccocus faecium résistant à la vancomycine dans un hôpital pédiatrique de soins de courte durée : Leçons tirées du dépistage environnemental et d'une étude cas-témoin

HISTORIQUE : La présente étude décrit l'enquête sur une éclosion d'entérocoque résistant à la vancomycine (ERV) et une étude cas-témoin pour repérer les facteurs de risque d'acquisition d'ERV dans un hôpital pédiatrique de soins tertiaires.

OBJECTIF : Faire un compte rendu de l'enquête sur une éclosion et une étude cas-témoin pour repérer les facteurs de risque de colonisation ou d'infection par l'ERV chez des enfants hospitalisés.

MÉTHODOLOGIE : Le dépistage des cas d'ERV s'est effectué par culture ou réaction en chaîne de la polymérase. Les auteurs ont entrepris une étude cas-témoin des patients colonisés par l'ERV. Ils ont procédé à un dépistage environnemental au moyen de cultures standard et de méthodes de susceptibilité, avec une électrophérèse en champ pulsé pour déterminer le lien entre les isolats d'ERV. Ils ont effectué l'analyse statistique au moyen du logiciel SAS version 9.0 (SAS Institute Inc., États-Unis).

RÉSULTATS : Les auteurs ont repéré 34 cas positifs à l'ERV dans dix services hospitaliers entre le 28 février et le 27 mai 2005. L'analyse par électrophérèse en champ pulsé a confirmé une seule souche d'éclosion, également isolée sur le jeu vidéo d'un service hospitalier touché. L'analyse multivariée a établi que l'utilisation de céphalosporine était le principal facteur de risque de colonisation par l'ERV.

CONCLUSIONS : Dans l'éclosion à l'étude, la colonisation par l'ERV s'associait de manière significative à l'utilisation de céphalosporine. Puisque le partage de jeux et les surfaces environnementales peuvent être colonisées par l'ERV, il faut en tenir particulièrement compte dans les protocoles d'entretien ménager, notamment dans les établissements pédiatriques.

of health care workers or others. Resistance to vancomycin is found primarily in Enterococcus faecium or Enterococcus faecalis; it is mainly transmitted by the vanA and vanB genes.

The control of VRE within acute care facilities requires an understanding of the selective forces driving the horizontal transmission of these organisms because most outbreaks have been shown to be clonally related. Several authors have found that risk factors for the acquisition of VRE include contact nation of the environment and subsequent spread via the hands

${ }^{1}$ Division of Microbiology, The Hospital for Sick Children, Toronto; ${ }^{2}$ Ontario Public Health Laboratories; ${ }^{3}$ The University of Toronto;

${ }^{4}$ Department of Paediatrics; ${ }^{5}$ Clinical Research Support Unit, The Hospital for Sick Children, Toronto, Ontario

Correspondence and reprints: Dr Anne G Matlow, Division of Infectious Diseases, The Hospital for Sick Children, 555 University Avenue,

Toronto, Ontario M5G 1X8. Telephone 416-813-8819, fax 416-813-4992, e-mail anne.matlow@sickkids.ca

Received for publication June 29, 2007. Accepted November 17, 2007 


\begin{tabular}{|c|c|c|c|c|}
\hline Risk factor & $\mathbf{P}$ & $\chi^{2}$ & OR & OR $(95 \% \mathrm{Cl})$ \\
\hline $\begin{array}{l}\text { Antibiotic use } \\
>4 \text { days }\end{array}$ & 0.01 & 3.8 & 3.7 & $1.3-10.5$ \\
\hline $\begin{array}{l}\text { End stage renal } \\
\text { disease }\end{array}$ & 0.12 & 2.4 & 6.0 & $0.6-57.7$ \\
\hline $\begin{array}{l}\text { Trimethoprim- } \\
\text { sulfamethoxazole }\end{array}$ & 0.05 & 4.0 & 3.5 & $1.0-11.0$ \\
\hline Stay on ward $X$ & 0.03 & 4.8 & 6.0 & $1.2-29.7$ \\
\hline Image-guided therapy & 0.05 & 3.7 & 3.0 & $1.0-9.0$ \\
\hline $\begin{array}{l}\text { Use of any } \\
\text { cephalosporin }\end{array}$ & 0.01 & 7.3 & 3.5 & $1.4-8.8$ \\
\hline Developmental delay & 0.16 & 2.0 & 0.5 & $0.2-1.3$ \\
\hline Current length of stay & 0.23 & 1.4 & 1.0 & $1.0-1.0$ \\
\hline Aminoglycoside use & 0.75 & 0.1 & 1.2 & $0.5-3.0$ \\
\hline Cystic fibrosis & 0.99 & 0.0001 & 1000 & $0.01-1000$ \\
\hline Clinic visits & 0.55 & 0.35 & 1.0 & $1.0-1.0$ \\
\hline Diarrhea & 0.15 & 2.1 & 0.5 & $0.2-1.3$ \\
\hline $\begin{array}{l}\text { Immunosuppressive } \\
\text { drug }\end{array}$ & 0.37 & 0.8 & 1.5 & $0.6-3.7$ \\
\hline Use of vancomycin & 0.13 & 2.3 & 2.2 & $0.8-5.9$ \\
\hline $\begin{array}{l}\text { Use of piperacillin- } \\
\text { tazobactam }\end{array}$ & 0.53 & 0.4 & 0.7 & $0.3-1.9$ \\
\hline
\end{tabular}

with infected or colonized patients or items used by those patients; immunosuppression; use of antibiotics, particularly vancomycin and cephalosporins; exposure to specific invasive procedures or indicators of overall health (1-3). The environment has been shown to be heavily contaminated with VRE in outbreaks of colonization or infection in children $(4,5)$, which explains the identification of 'exposure to an environment previously occupied by a VRE-positive patient' as a risk factor for acquisition (6). The primary aim of the present study was to describe an outbreak investigation and a case-control study with an emphasis on the identification of risk factors for VRE colonization or infection in hospitalized children.

\section{PATIENTS, SETTING AND METHODOLOGY}

The Hospital for Sick Children (HSC) in Toronto is a 300-bed tertiary care pediatric hospital serving the Canadian province of Ontario (population 12.5 million); it admits referred patients from across Canada. The first known case (colonized or infected) of VRE at the HSC was identified in the spring of 2005.

Before the outbreak, routine screening for VRE was performed on stool samples sent for Clostridium difficile toxin assay $(7,8)$. Once the outbreak was identified, screening of known contacts and all patients on affected wards was performed at intervals. VRE-positive patients were placed in contact precautions, and extensive environmental cleaning was undertaken. When possible, the movement of VRE-positive patients was controlled, and contaminated items were embargoed. Aggressive contact tracing and screening of stools for VRE by culture or, in cases of time constraint, by polymerase chain reaction for $\operatorname{van} \mathrm{A} / \operatorname{van} \mathrm{B}$ resistance determinants (Lightcycler VRE Detection Kit, Roche Molecular Systems Inc, USA) were performed on patients with a suspected epidemiological link to the index patient (8). Environmental surveillance from wards linked to VRE-positive patients was done by swabbing (Amies media with charcoal) environmental sites at the height of the outbreak in selected rooms of selected wards. Randomly chosen high-touch surfaces (ie, toilet facilities, beds, walls, common equipment, door handles, floors, televisions and remote controls, shelves, books, toys, carts, keyboards and computer equipment) in all rooms and common areas of wards with VRE-positive patients were swabbed. Swabs were incubated for $24 \mathrm{~h}$ in brain heart infusion broth at $35^{\circ} \mathrm{C}$. The broth $(100 \mu \mathrm{L})$ was then inoculated onto mEnterococcus agar medium and incubated for $72 \mathrm{~h}$ at $35^{\circ} \mathrm{C}$. Cultures were examined daily for growth, and suspect colonies were identified according to standard protocols (9). Antibiotic susceptibility testing and interpretation were undertaken using the Clinical and Laboratory Standards Institute-approved methodologies and breakpoint guidelines (7). Pulsed-field gel electrophoresis (PFGE) was carried out and interpreted according to Tenover et al's criteria (10).

The health records department undertook computerized control matching to identify controls while maintaining patient confidentiality. For the case-control study, a case was defined as any patient with culture-verified VRE colonization of the rectum or stool between January 1, 2005, and May 27, 2005. Control patients were the next two direct admissions to an affected ward who were VRE-negative with the closest duration of length of stay to the matched VRE-positive patient. A review of the literature led to the creation of a chart review screening tool, which was a checklist of risk factors for VRE colonization identified from previously published literature $(1-3,6)$ used for the investigation of the outbreak. Potential risk factors for VRE colonization or infection included patient age, previous hospitalization, immunosuppression, antibiotic use, use of specific therapeutic agents, invasive devices and specific procedures. Other risk factors tested in this study are listed in Table 1.

Before initiation of the chart review, the study was approved by the HSC Research Ethics Board. Univariate and multivariate statistical analyses were performed using SAS version 9.0 (SAS Institute Inc, USA). Multivariate analysis used an analysis of maximum likelihood estimates, OR point estimates and the Wald confidence intervals for adjusted ORs. Variables tested by multivariate analysis included antibiotic use for more than four days, image-guided therapy (IGT) and the use of any cephalosporin.

\section{RESULTS}

Epidemiological and microbiological characteristics

Following the identification of the index case of VRE on a hematology-oncology ward, 33 patients who had been hospitalized on 10 wards were further identified between February 28, 2005, and May 27, 2005 (Figure 1). No new VRE cases were identified in the last 30 days of the outbreak. Intensified outbreak screening and time-course analysis indicated that the majority of VRE-positive patients (29 of 34 [85\%]) were identified between days 19 and 41 of the outbreak. Of the over 1800 potential contacts, most had already been discharged. The one-third remaining in hospital were screened for VRE colonization. There were no episodes of clinical infection in patients colonized with VRE, and all cases were identified as 'VRE carriers' from culture and/or polymerase chain reaction of either rectal swabs or stool samples. All VRE isolates were identified as E faecium and were shown to carry the vanA resistance determinant. Strain typing of VRE by PFGE detected a single clone associated with all patients. 


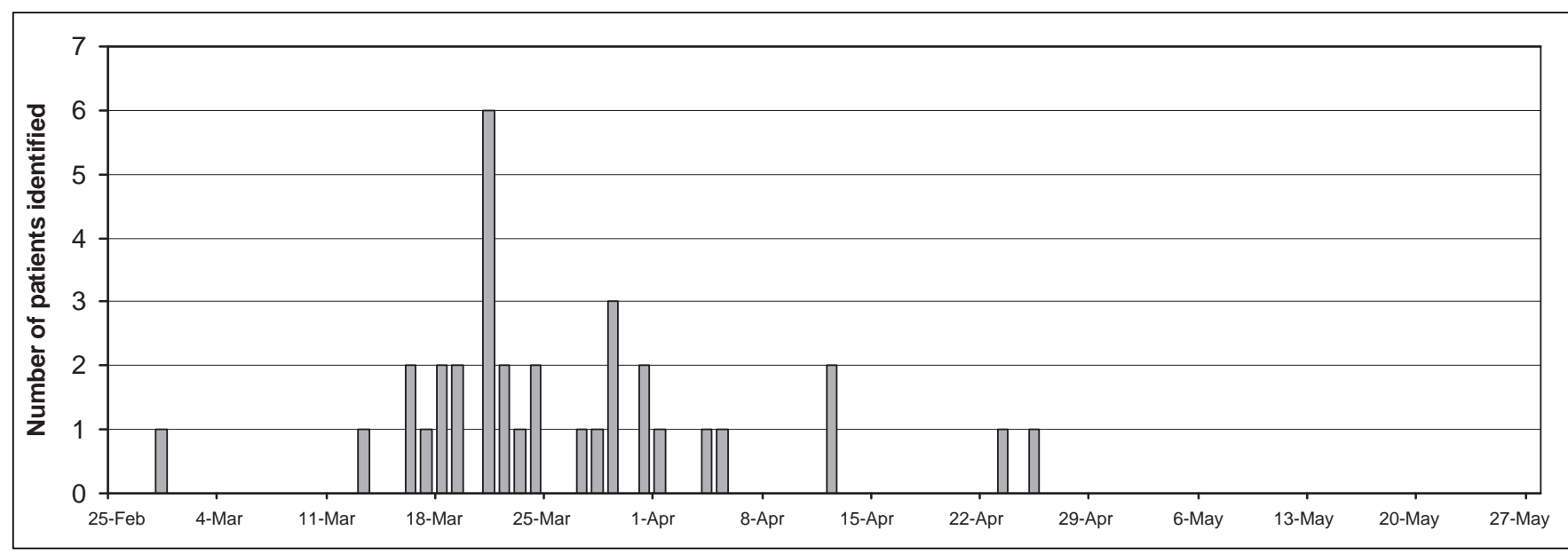

Figure 1) Epidemiological curve of vancomycin-resistant enterococci outbreak in an acute care pediatric hospital. Apr April; Feb February; Mar March

\section{Environmental findings}

The only environmental site from which VRE were detected (one of 192) was the surface of a video game system in the playroom of an affected ward. The VRE strain isolated from the video game was indistinguishable from 29 patient strains by PFGE, and was closely related (two-band difference) to the remaining patient strains.

\section{Case-control matching and univariate analysis}

Case-control matching was possible for 33 of 34 cases of VRE colonization. Using univariate analysis, significant risk factors that were identified included the use of antibiotics for more than four days, the use of trimethoprim-sulfamethoxazole, stay on one ward which had the highest incidence of VRE cases, having undergone IGT and the use of any cephalosporin (Table 1).

\section{Multivariate analysis}

Multivariate ANOVA indicated that VRE colonization was predominantly associated with the use of any cephalosporin $\left(\mathrm{P}=0.03, \chi^{2}=5.0, \quad \mathrm{OR}=3.1, \quad \mathrm{OR} 95 \% \mathrm{CI} 1.1\right.$ to 8.3$)$. Multivariate ANOVA did not find an association between VRE and antibiotic use of more than four days $(\mathrm{P}=0.09$, $\chi^{2}=2.9, \mathrm{OR}=2.6$, OR $95 \% \mathrm{CI} 0.9$ to 7.9$)$, or having undergone IGT $\left(\mathrm{P}=0.14, \chi^{2}=2.2, \mathrm{OR}=2.6\right.$, OR 95\% CI 0.7 to 9.3$)$.

\section{DISCUSSION}

The present study is the first published description of a VRE outbreak investigation in a Canadian pediatric acute care institution, although reports in children's hospitals have been reported worldwide. Similar to this outbreak, which was first identified in a hematology-oncology population, most previously described outbreaks and surveillance studies of VRE in pediatric hospitals have identified hematology-oncology patients as key reservoirs of VRE; reports of outbreaks in children in neonatal intensive care units have also been reported $(4,5,11,12)$. For example, following the introduction of surveillance screening in the United Kingdom, Gray and George (4) found colonization with VRE in $38.3 \%$ of hematology-oncology patients and in $11.1 \%$ of hepatology-gastroenterology patients, but in only $2.3 \%$ of children in the pediatric intensive care unit and $1.5 \%$ of children in the renal unit. Other characteristics of the outbreak described here are similar to those previously reported in terms of risk factors, duration, number of patients involved and the use of control measures.

Pediatric VRE outbreaks in other institutions have been associated with antibiotic use; for example, one outbreak of 14 patients (19\% of those screened) on an oncology ward was associated with prolonged treatment with teicoplanin, ceftazidime or amikacin (5). In this report, the authors identified cephalosporin use as the key risk factor for VRE colonization. It is postulated that cephalosporin use may give VRE a selective advantage in the intestinal tract, thereby increasing the load of VRE that is transmitted between patients either by inanimate objects or the hands of health care workers (13). Findings like this have led to the idea that antibiotic stewardship may play a role in limiting the spread of VRE in hospitals by controlling antibiotic prescribing and/or the class of antibiotics used (13). However, this remains unproven, as does the hypothesis that certain antibiotics may actually be used to prevent a selective advantage for VRE colonization (14).

Other outbreaks in pediatric institutions have described much heavier environmental contamination than we observed in our outbreak (ie, $25 \%$ to $70 \%$ of samples testing positive) $(4,5)$. If the environment was an important factor in transmission in our study, we might have missed the heavily contaminated areas due to the commencement of enhanced cleaning by the time environmental screening was performed. Alternatively, mobile or shared elements, such as the video game system, might have played a larger role in our outbreak than in others. Previous studies indicated that VRE can survive for prolonged periods of time on inanimate surfaces (15), and that occupancy of an environment previously used to house a VRE-positive patient is a risk factor for VRE acquisition (6). Thus, environmental decontamination is important in controlling outbreaks of VRE. In one study (5), the use of stringent infection control measures successfully reduced environmental contamination rates from $25 \%$ of samples in week 1 to none in week 11, which was the length of time it took to control the outbreak. Although the impact of individual control measures in our outbreak was not formally evaluated, the use of active surveillance, enhanced infection control measures and molecular testing were in line with previously reported efforts to control VRE outbreaks, and were clearly successful in ours $(5,16,17)$. 
Since our investigation, patients admitted to the hematologyoncology ward are actively screened for VRE and isolated with contact precautions if positive. We have had no evidence of further nosocomial spread of colonized patients admitted to hospital and no further outbreaks. Good antibiotic stewardship and judicious antibiotic use is reinforced by our institution's antibiotic utilization committee. Currently, in the course of housekeeping and environmental disinfection, particular attention is paid to frequently touched surfaces and objects, including mobile toys

\section{REFERENCES}

1. Gearhart M, Martin J, Rudich S, et al. Consequences of vancomycin-resistant Enterococcus in liver transplant recipients: A matched control study. Clin Transplant 2005;19:711-6.

2. McNeil SA, Malani PN, Chenoweth CE, et al. Vancomycinresistant enterococcal colonization and infection in liver transplant candidates and recipients: A prospective surveillance study. Clin Infect Dis 2006;42:195-203.

3. Hwang YS, Brinton BG, Leonard RB, Blue SR, Woods ML, Carroll KC. Investigation of an outbreak of vancomycin-resistant Enterococcus faecium in a low prevalence university hospital. J Investig Med 1998;46:435-43.

4. Gray JW, George RH. Experience of vancomycin-resistant enterococci in a children's hospital. J Hosp Infect 2000;45:11-8.

5. Nourse C, Murphy H, Byrne C, et al. Control of a nosocomial outbreak of vancomycin resistant Enterococcus faecium in a paediatric oncology unit: Risk factors for colonisation. Eur J Pediatr 1998;157:20-7. (Erratum in 1998;157:405).

6. Huang SS, Datta R, Platt R. Risk of acquiring antibiotic-resistant bacteria from prior room occupants. Arch Intern Med 2006;166:1945-51.

7. National Committee for Clinical Laboratory Standards. Methods for dilution of antimicrobial susceptibility tests for bacteria that grow aerobically - Approved standard M7-A6. Wayne: NCCLS, 2003.

8. Drews SJ, Johnson G, Gharabaghi F, et al. A 24-hour screening protocol for identification of vancomycin-resistant Enterococcus faecium. J Clin Microbiol 2006;44:1578-80.

9. Division of Nosocomial and Occupational Infectious Diseases, Bureau of Infectious Diseases, Laboratory Centre for Disease Control, Health Canada; VRE Working Group, Canadian Hospital Epidemiology Committee. Preventing the spread of and games. In a pediatric setting, the latter are of particular importance because despite policies to the contrary, it is hard to control access to these highly desired objects.

ACKNOWLEDGEMENTS: The authors thank other members of the VRE outbreak investigation team (Margaret Roscoe, Toula Myriklis, Farhad Gharabaghi, Jeff Fuller, Yvonne Yau, Raymond Tellier and the Bacteriology Laboratory) for their enormous effort in helping to control this outbreak.

vancomycin-resistant enterococci (VRE) in Canada. Can Commun Dis Rep 1997;23(Suppl 8):i-iv,1-16,i-iv,1-19.

10. Tenover FC, Arbeit RD, Goering RV, et al. Interpreting chromosomal DNA restriction patterns produced by pulsed-field gel electrophoresis: Criteria for bacterial strain typing. J Clin Microbiol 1995;33:2233-9.

11. Borgmann S, Niklas DM, Klare I, et al. Two episodes of vancomycin-resistant Enterococcus faecium outbreaks caused by two genetically different clones in a newborn intensive care unit. Int J Hyg Environ Health 2004;207:386-9.

12. Lee HK, Lee WG, Cho SR. Clinical and molecular biological analysis of a nosocomial outbreak of vancomycin-resistant enterococci in a neonatal intensive care unit. Acta Paediatr 1999;88:651-4.

13. Armeanu E, Bonten MJ. Control of vancomycin-resistant enterococci: One size fits all? Clin Infect Dis 2005;41:210-6.

14. Stiefel U, Paterson DL, Pultz NJ, Gordon SM, Aron DC, Donskey CJ. Effect of the increasing use of piperacillin/tazobactam on the incidence of vancomycin-resistant enterococci in four academic medical centers. Infect Control Hosp Epidemiol 2004;25:380-3.

15. Lankford MG, Collins S, Youngberg L, Rooney DM, Warren JR, Noskin GA. Assessment of materials commonly utilized in health care: Implications for bacterial survival and transmission. Am J Infect Control 2006;34:258-63.

16. Singh N, Léger MM, Campbell J, Short B, Campos JM. Control of vancomycin-resistant enterococci in the neonatal intensive care unit. Infect Control Hosp Epidemiol 2005;26:646-9.

17. Malik RK, Montecalvo MA, Reale MR, et al. Epidemiology and control of vancomycin-resistant enterococci in a regional neonatal intensive care unit. Pediatr Infect Dis J 1999;18:352-6. 


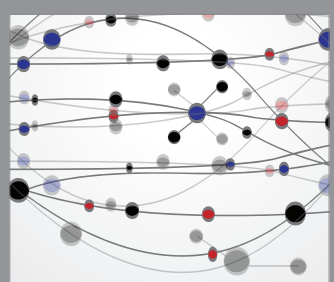

The Scientific World Journal
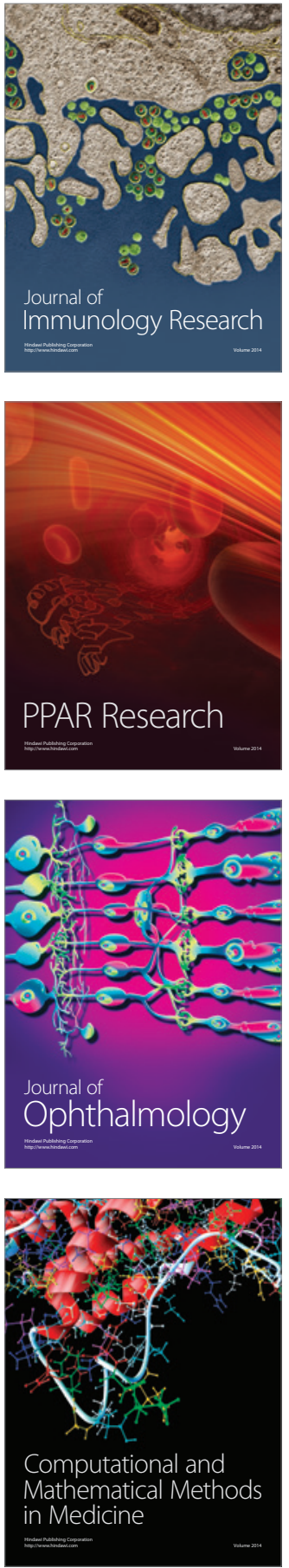

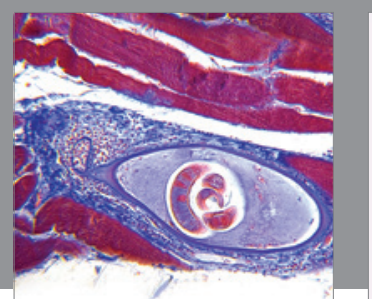

Gastroenterology Research and Practice

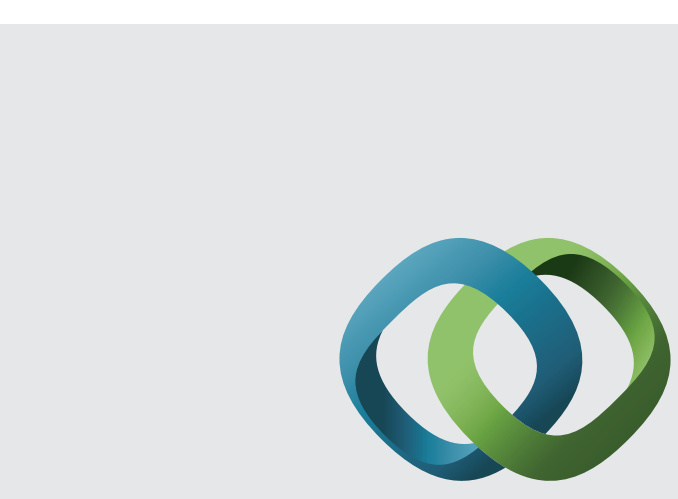

\section{Hindawi}

Submit your manuscripts at

http://www.hindawi.com
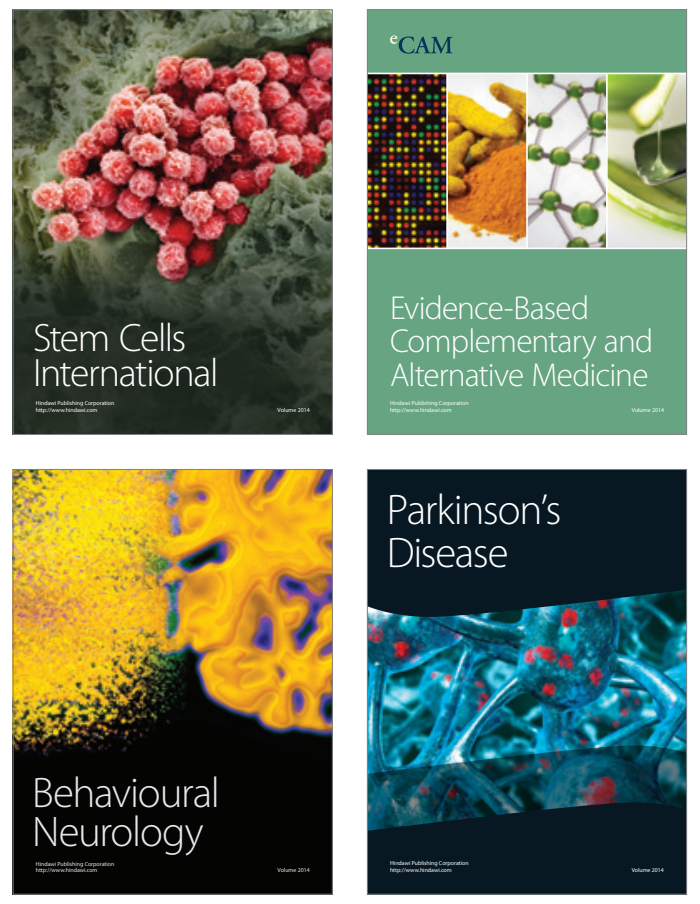
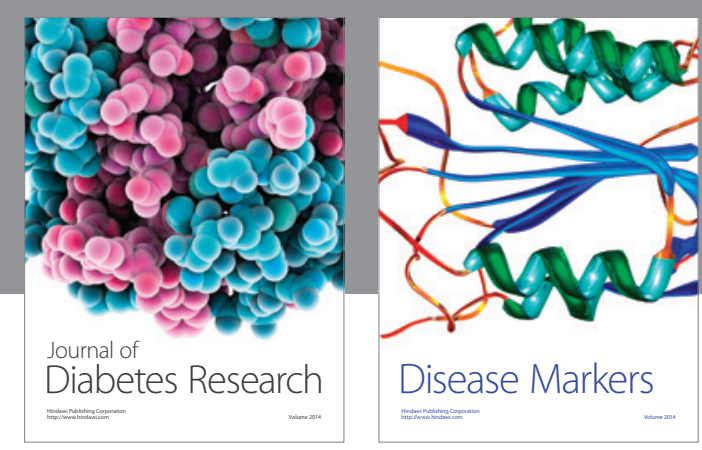

Disease Markers
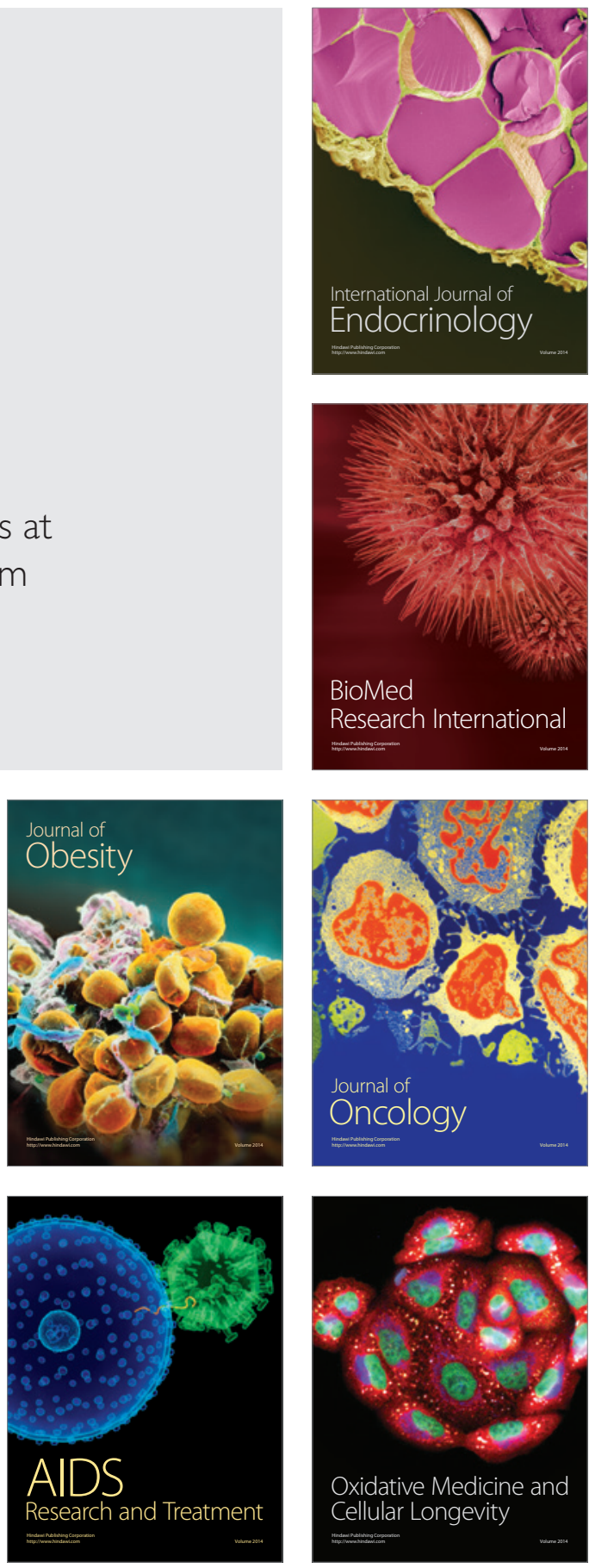